\title{
Universidad y Ética
}

René Edgardo Vargas

Investigador UTEC

\section{Resumen}

En este artículo se plantea la problemática actual acerca de los principios y valores que la ética del tener y el mercadocentrismo han inculcado a los individuos dentro del tejido social de nuestro mundo en general pero de El Salvador en particular. ¿ES viable producir dirigentes capaces de ejercer un liderazgo solidario y probo en los asuntos públicos ante la divinización del mercado? ¿Cuál es la posibilidad de que las Universidades puedan formar profesionales que actúen en servicio de la sociedad y del bien común con un entorno tan desfavorable? ¿Qué pueden y deben hacer las Universidades para elevar el nivel ético de docentes, estudiantes y el resto de su recurso humano?

\section{Introducción}

E problema de la Ética se ha convertido en un tema de mucha relevancia en nuestro país ante la cada vez mayor contaminación del tejido social; la aprobación de la denominada "Ley de Ética gubernamental" en el 2006 (reformada en el 2008), la necesidad de cumplir con el compromiso adquirido por El Salvador al ratificar en 1998 la Convención Interamericana contra la corrupción y la suscripción de convenios para combatirla, así como las responsabilidades contraídas de conformidad con el Tratado Marco de Seguridad en Centro América, son parte del orden normativo desde el cual se están tratando de enfrentar la multiplicidad de problemas sociales internos y regionales.

Por su parte, la mayoría de nuestras Universidades incluyen en sus programas como materia de estudio la Ética, de allí la elección del título para este breve artículo, cuyo objetivo general es demostrar la enorme distancia que existe entre la teoría y la práctica diaria en la red de relaciones sociales en general y en las de los distintos actores que participamos en la constante dinámica del quehacer universitario en particular. Específicamente se pretende: 1) evidenciar que los principios éticos no se imponen mediante leyes. 2) Res- ponder a la interrogante sociológica de ¿Por qué actuamos de una determinada manera y no de otra?

La importancia que los griegos le dieron a la búsqueda de respuestas a la interrogante antes expresada evidencia la complejidad del problema; Aristóteles - por ejemplo - en sus trabajos sobre la ética trató de dar una respuesta teórica acerca de qué es lo bueno, cuál era el deber ser o el contenido de esa categoría, pero sin plantearse cómo debía de actuar el ser humano en cada situación concreta, pues para él tales decisiones correspondían al comportamiento moral-práctico y por tanto cada individuo debía asumir las consecuencias de sus actos como ser responsable. 
Contrario a este enfoque, que incluso motivó a algunos estudiosos del tema a considerar a la Ética como un apartado de la Filosofía con carácter especulativo, apareció la visión normativista, asignándole como su razón de ser la de señalar la conducta mejor en sentido moral y formular pautas de comportamiento, tendencia que indudablemente se ha impuesto en el actual contexto de nuestra sociedad. Esta segunda interpretación ha dado pie a enunciar la siguiente hipótesis de trabajo: "Los principios éticos son articulados para justificar realidades concretas, convirtiéndose en expresión ideológica de una moral determinada, concretada mediante normas".

\section{LA REALIDAD DE NUESTROS TIEMPOS}

Como se menciona en la introducción, el tema de la Ética ha cobrado relevancia en nuestro país, convirtiéndose en caja de resonancia tanto a nivel coloquial como de instituciones educativas, empresariales e incluso del mismo gobierno; sin embargo, opino que los planteamientos contenidos en los distintos aportes orientados a la búsqueda de soluciones a la multiplicidad de problemas de El Salvador están fundamentados en considerar que el camino adecuado es el de leer la biblia, establecer reglamentos o privilegiar el derecho represivo, evidenciando un enfoque sim- plista para una situación tan compleja por su origen multicausal.

Los hechos de nuestro diario acontecer hablan por sí solos de un cuerpo social gravemente enfermo; fiestas de éxtasis y otras drogas en casas de playa con la participación de jóvenes de diversos estratos sociales, falsificadores de moneda, traficantes de menores, asesinatos con armas de fuego $u$ otros instrumentos de muerte empleados para desmembrar sádicamente, aumentos de salarios inconsultos a algunos funcionarios públicos, títulos falsos, corrupción en la administración de justicia, lavado de dinero, estafadores de distinta índole, son solo algunos hechos que caracterizan a esa "tormenta tóxica" que invade y envenena a nuestro cuerpo social, cuya máxima expresión ha sido alcanzada con la reciente que- ma de un bus con todo y sus ocupantes ante la horrorizada contemplación de propios y extraños, lo que conlleva a la necesidad de cuestionarnos sobre lo siguiente: ¿a dónde están las causas de tan preocupante situación? ¿Por qué nuestra sociedad ha alcanzado tal nivel de degradación? ¿Cuál es el papel de los distintos agentes de socialización en este proceso de descomposición del tejido social?

La búsqueda de respuestas debe partir de aceptar una premisa filosófica y sociológica: el comportamiento humano está sumamente influenciado por los cambios de su entorno y las históricas contradicciones entre el deber ser y el ser. En la democracia griega, cuyo substrato filosófico político era la búsqueda del bien común y la Polis con el poder para alcanzarlo, el individuo estaba su-

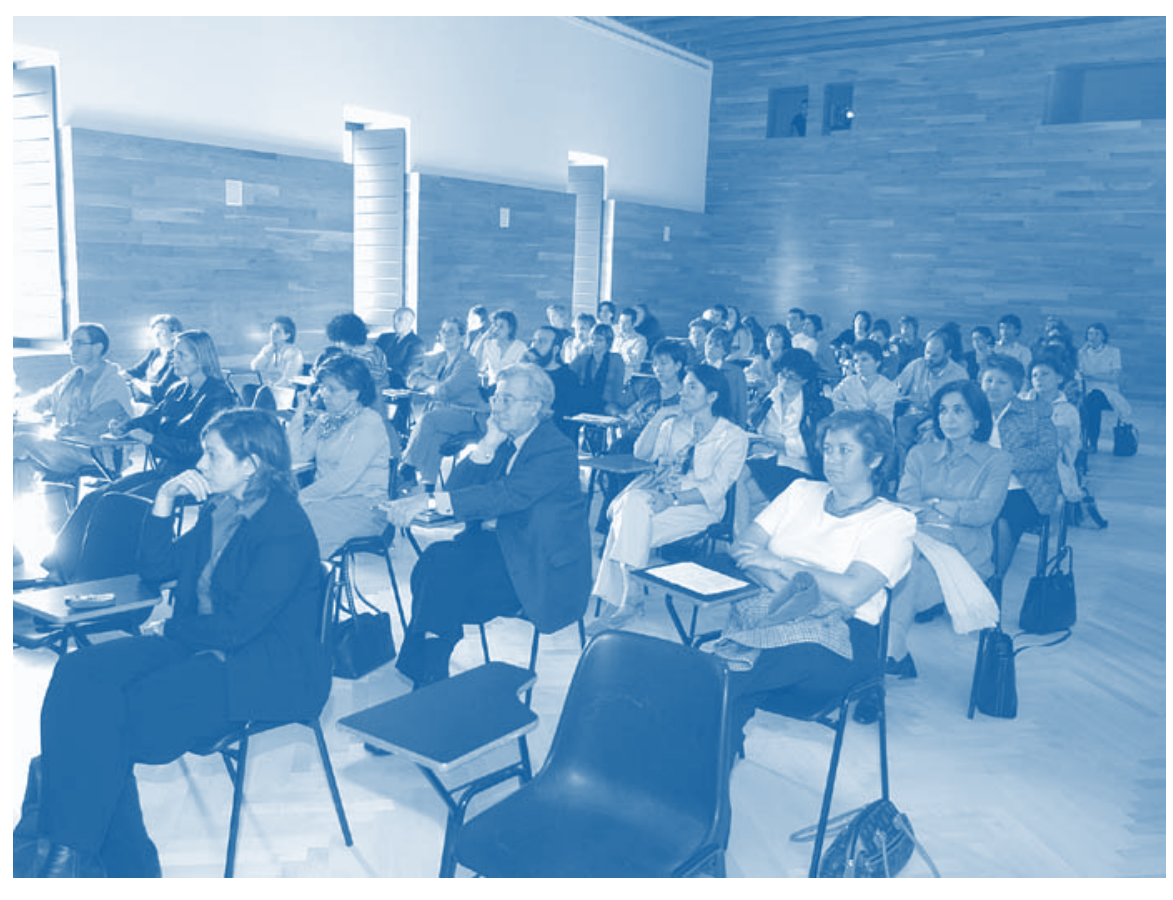


jeto a los designios del Estado; en la alta edad media la ley divina debía regir la conducta humana, enfoque teológico elaborado por San Agustín en su obra "la cuidad de Dios", proclamando con ello la superioridad de la autoridad y organización eclesiástica sobre el poder temporal. Con el advenimiento del renacimiento y la ilustración surgió el pensamiento filosófico racionalista $y$ antropocentrista, colocando a la persona como la razón de ser de la filosofía política, visión que se fue transformando con el avance y consolidación del capitalismo dentro del estado de la modernidad nacido del derecho e impulsado por el liberalismo económico y su premisa del "dejar hacer, dejar pasar" y la ética del tener, expresada en el aforismo "tanto tienes tanto vales, nada tienes nada vales". Toda esta estructura de pensamiento convirtió al ser humano de sujeto a objeto del Estado, exaltando el comportamiento individualista.

Ante los conflictos permanentes del modelo liberal a consecuencia de lo que los sociólogos denominaron "Darwinismo social", surgió el Estado de bienestar como la opción para superar el problema de la pobreza; sin embargo, el pensamiento liberal habría de tomar revancha y con una crítica virulenta sobre la economía social de mercado impuso el pensamiento neoliberal dentro de la denominada globalización como nueva fase del capitalismo.
Cada una de esas etapas condicionaron el comportamiento social del ser humano, estableciéndose una disyuntiva entre el ser solidario y su contrario, la individualidad; al imponerse el segundo sobre el primero, la ideología imperante desarrollo una actitud narcisista sobre nuestra sociabilidad, promoviendo el consumismo a ultranza. Para complicar más el escenario interno, el modelo neoliberal se comenzó a implementar luego de una cruenta guerra de un poco más de 12 años y su estela de destrucción material, incalculable pérdida de vidas, concentración poblacional ante los movimientos internos, fragmentación de la familia producto de las migraciones y toda una secuela Sicosocial, por ahora muy poco investigada.

Nuestros centros educativos en general y las universidades en particular, se encuentran anegados en ese ambiente, por tanto, contaminados por sus efectos desde la Ética del tener; sin embargo, en lo que a los centros de educación superior se refiere, inmersos en sus propios problemas, parecen haber perdido la perspectiva de su compromiso histórico, tal como lo manifestara el Rector de la Universidad de Harvard:

"A pesar de la importancia que tiene el desarrollo moral del individuo y de la sociedad, no puede afirmarse que la educación superior haya demostrado un profundo interés por el tema. Pero algunos escándalos públicos recientes inducen a pensar que el Alma Mater debe proporcionar algo más que meros conocimientos teóricos y prácticos"

En la revista selecciones de Noviembre de 2006 tuve la oportunidad de leer un artículo titulado "trampas, pero si todos lo hacen". En él se cuenta la historia de una estudiante mejicana que habiendo mantenido un rendimiento aceptable durante su carrera fue sorprendida tratando de copiar en su examen de Geografía Económica, una de las últimas materias para egresar. La autora del artículo, Sicóloga María Antonia Valle, en un primer nivel de su investigación concluye diciendo: "Mientras que ésta estudiante y su profesor saben que se trató de una improvisada y pésima decisión, lo triste del asunto es que no se trata de un caso aislado; las trampas académicas son una epidemia en las preparatorias y universidades del país". En el material sobre un curso de ética se afirma lo siguiente: "En una encuesta efectuada en la década de los noventa en Minnesota por el grupo Pinnacle, $59 \%$ de los estudiantes encuestados dijeron que con gusto aceptarían una suspensión de 6 meses, con tal de poder efectuar un negocio ilícito de \$10 millones".

Mi experiencia como estudiante y docente de educación superior me permite afirmar que las referencias anteriores son familiares a todos los sec- 


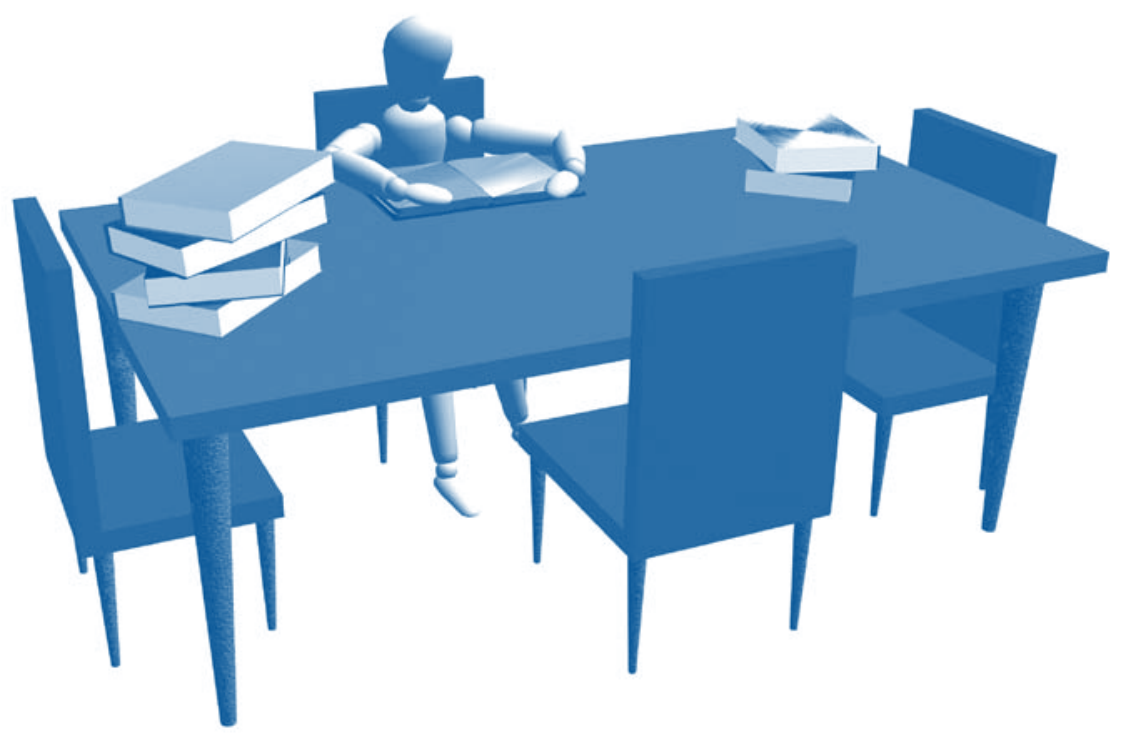

tores involucrados en las instituciones educativas, e incluso podríamos contar las nuestras, pero basten ellas para evidenciar la relación causa-efecto en la analogía entre Universidad y mercado, como reproducción de lo que sucede a nivel Macro sociológico en la interacción Estado-mercado.

La Ética del tener ha sido, dentro del neoliberalismo, la motivación económica de la acción social para aplicar mecánicamente la afirmación política de Maquiavelo de que "el fin justifica los medios", lo que implica aceptar cualquier tipo de actuación siempre que permita lograr "ser" en la sociedad mediante el "tener. Frente a estas tendencias de comportamiento social, surgen diversas interrogantes que atañen a la sociedad en general y a nuestras universidades en particular : ¿Cuál es la posibilidad de que las Universidades puedan formar profesionales que actúen en servicio de la sociedad y del bien común con un entorno tan desfavorable? ¿Qué pueden y deben hacer las Universidades para elevar el nivel ético de docentes, estudiantes y el resto de su recurso humano?

\section{EN BUSQUEDA DE RESPUESTAS}

Debemos comenzar por comprender que la Ética es esencial para nuestra sobrevivencia, por tanto, no constituye una moda o una opción coyuntural a resolver exclusivamente con leyes 0 reglamentos, sino una exigencia personal fundamental para lograr una formación integral; desde esta perspectiva, el principio filosófico que ha de orientar el quehacer universitario debe ser la búsqueda de la verdad a través del co- nocimiento. Para contribuir a impulsar una revolución Ética en nuestro país, la sociedad en general y nuestros centros de estudio en particular, deben comenzar por buscar respuestas acerca de la verdad histórica salvadoreña, en el entendido de que a ella llegaremos por aproximaciones.

Propongo como marco conceptual definir la ética como: "La teoría o ciencia del comportamiento moral de los hombres en sociedad" ; desde esta perspectiva: "la tarea fundamental de la Ética es la de toda teoría, o sea, explicar, esclarecer o investigar una realidad dada produciendo los conceptos correspondientes" Ello nos permitiría estudiar la Ética desde su carácter científico y racional; respecto del primero, posibilita elaborar modelos que indican cómo debería comportarse la realidad, construyendo un tipo ideal. Respecto de lo segundo, porque sus paradigmas nos proporcionan causas del porqué ciertas conductas son buenas y otras son malas.

Partiendo de la tesis de que en todos los hechos antes mencionados se han visto involucradas personas que en algún momento estuvieron registradas como estudiantes, hemos de concluir que los cursos de Ética fueron simple expresión del deber ser, superados por la moral impuesta desde el mercado mediante una escala de valores que mueve al conjunto de la sociedad hacia 
la búsqueda del bienestar económico sin importar los medios, al logro del prestigio personal mediante la ética del tener, al abuso del poder que confieren determinados títulos o cargos para satisfacer intereses personales, al tratar de resolver los problemas con fórmulas inmediatistas, a la pérdida del reto de largo plazo para crear una visión filosófica que le dé verdadero sentido a la vida.

Se impone -entonces - de manera impostergable, reorientar la enseñanza de la Ética como un conjunto de principio teóricos que cada quien asume como propios y no como una serie de reglas de moralidad que se imponen por decreto; de allí la exigencia del esfuerzo académico por politizar al ciudadano, estimulando a preocuparse por los problemas de la cosa pública e incentivando su conciencia crítica para un adecuado razonamiento al enfrentarse a los problemas de su diario hacer, posibilitándole el tomar mejores decisiones y el poder participar activamente en la dinámica nacional, pero también permitiéndole aprender a asumir la responsabilidad por las consecuencias de sus actos

He aquí el hilo conductor de la educación en todos sus niveles, lo que exige una preocupación constante por despertar en docentes y estudiantes especial interés en el conocimiento científico, en la investigación y en los problemas de la sociedad, provocando con ello una ruptura con los paradigmas tradicionales del siglo $X X$ de estudiar para pasar y de la enseñanza repetitiva, memorística y conductista. Pero también implica el que par la enseñanza de la Ética se diseñen creativamente técnicas pedagógicas orientadas a provocar en los alumnos un verdadero interés en la materia, superando ese otro paradigma de verla como irrelevante para sus propósitos futuros; dos principios me parecen fundamentales: 1) El docente ha de ser un orientador, un educador y un facilitador, que sepa predicar con el ejemplo. 2) Su conocimiento sobre el tema ha de permitirle desarrollar un curso de Ética aplicada con un marco teórico desde el cual los estudiantes puedan discutir críticamente sobre problemas de la vida real como el aborto, los matrimonios entre personas del mismo sexo, la eutanasia, las maras, el soborno, en fin, cuestiones prácticas que han de enfrentar una vez incorporados como población económicamente activa y que les han de exigir, más que respuestas correctas, la sensibilidad necesaria para tomar la mejor decisión posible dentro de un adecuado pensamiento ético.

\section{CONCLUSIONES}

Resulta evidente la necesidad de una revolución Ética de tratamiento inten- sivo para sanar a nuestro maltrecho cuerpo social, y las Universidades en El Salvador deben asumir el compromiso de llevar adelante dicha revolución; claro está que no son los únicos actores en la puesta en marcha de la lucha por el rescate social, pero constituyen una pieza fundamental del sistema, por cuanto han adquirido el compromiso de formar a las nuevas generaciones que posteriormente tendrán la responsabilidad de decretar leyes, administrar empresas, aplicar los conocimientos de la biotecnología, viajar al espacio, pilotear aeronaves, gobernar y toda otra multiplicidad de roles para posibilitar la construcción de una sociedad justa, libre, participativa y armónica, dentro de Estados inspirados por la puesta en práctica de los principios democráticos, en donde impere el respeto al sistema jurídico como el medio idóneo para la solución pacifica de los normales conflictos y contralor del poder para evitar los abusos del pasado.

Nuestras universidades deben abanderar ese esfuerzo y apoyar decididamente el reto que Benedicto XVI ha lanzado al mundo en su nueva encíclica al afirmar que: "La crisis nos obliga a revisar nuestro camino, a darnos nuevas reglas y a encontrar nuevas formas de compromiso" 